\title{
DISPERSĀO DE BIOMPHALARIA STRAMINEA, HOSPEDEIRA INTERMEDIARIA DO SCHISTOSOMA MANSONI, ATRAVÉS DA DISTRIBUIÇÃO DE PEIXES (1)
}

\author{
Renato de R. CORREA (2) $e^{\cdot(4)}$ \\ José Mauricio de Toledo MURGEL (3) \\ José de Toledo PIZA (4) \\ Alberto da Silva RAMOS (4) \\ Luiz Cândido de Souza DIAS (4) \\ Lúcia Vieira C. MORAIS (5) \\ Felipe Francisco do ROSARIO (2)
}

CORRÊA, R. de R. et al. - Dispersão de Biomphalaria straminea, hospedeira intermediária do Schistosoma mansoni, através da distribuição de peixes. Rev. Saúde públ., S. Paulo, 4:117-27, dez. 1970.

Resumo: Foi focalizado, pela primeira vez o encontro de $B$. straminea no Estado de São Paulo. Esta espécie vem juntar-se aos planorbídeos já assinalados em nosso Estado. Foram descritos os criadouros, onde a $B$. straminea foi coletada, localizados em tanques de criação de peixes nas Estaçōes de Piscicultura de Barra Bonita e Americana, Estado de São Paulo, e em um aquário particular na capital dêsse Estado. Fêz-se referência ao transporte de peixes oriundos de zonas do país onde ocorre aquela espécie, Amazonas e Ceará, como responsável pela introdução daquele molusco no Estado. Destacou-se êsse achado pelo perigo que representa a distribuição de peixes da maneira como vem sendo feita atualmente em nosso país, tendo sido julgado necessário o estabelecimento de quarentena para aquêles vindos de zonas infestadas por espécies hospedeiras intermediárias do $\mathbf{S}$. mansoni. Foram relatadas as medidas de combate aos caramujos efetuadas imediatamente após aquela descoberta e os resultados obtidos. Conclui-se que a dispersão passiva da $B$. straminea pelo transporte de peixes, deve ampliar a distribuição geográfica dêsse planorbídeo, já assinalado na Venezuela, Guianas e no Brasil, sendo que neste último ocorre em tôdas as Unidades Federativas, exceto, no Rio Grande do Sul, Santa Catarina, Rio de Janeiro e Territórios.

Recebido para publicacão em 4-9-1970.

(1) Da Companhla de Combate a Esquistossomose da Secretaria da Saúde do Estado de São Paulo - São Paulo, S.P., Brasil. Apresentado em sessão do Departamento de Higlene e Mediclna Tropical da Associacão Paulista de Medicina em 4-12-1969.

(2) Da Divisão de Combate a vetores da Secretaria da Saúde do Estado de são Paulo - São Paulo, S.P., Brasil.

(3) Da Estacão Experimental de Biologia e Piscicultura da Secretaria da Agricultura - Barra Bonita, S.P., Brasil.

(4) Da Campanha de Combate à Esquistossome da Secretaria da Saúde do Estado de São Paulo e da Escola Paulista de Medicina - São Paulo, S.P., Brasil.

(5) Do Instituto Adolfo Lutz - Săo Paulo, S.P., Brasil. 
CORREA, R. de R. et al. - Dispersão de Biomphalaria straminea, hospedeíra intermediária do Schistosoma mansoni, através da distribuição de peixes. Rev. Saúde públ., S. Paulo, 4: 117-27, dez. 1970.

\section{N T R O D U C A O}

A dispersão passiva de moluscos, inclusive hospedeiros intermediários do Schistosoma mansoni por meio de aves aquáticas e plantas flutuantes tem sido observada por vários pesquisadores. (REY $\left.{ }^{6}, 1956\right)$. Verificamos a presença de planorbídeos dos gêneros Biomphalaria e Drepanotrema em raízes de aguapés (gêneros Eichhornia e Pontelerea) que poderiam funcionar como veículos para o transporte dêsses caramujos (Fig. 1).

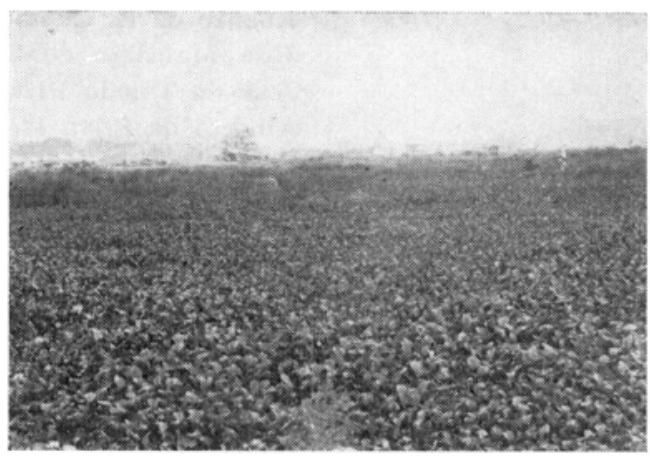

Fig. 1 - Lagoa com aguapés onde foram localizados exemplares de $B$. tenagophila, situa* da no Bairro do Limão em São Paulo.

\section{OBSERVACOES GERAIS}

Recentemente, em virtude de comunicado da Divisão de Pesca Interior do Instituto de Pesca da Secretaria da Agricultura do Estado de São Paulo, tivemos conhecimento, em 28 de maio de 1969, da existência de grande número de planorbídeos nos tanques de criação de peixes da Estação Experimental de Biologia e Piscicultu. ra de Barra Bonita, Estado de São Faulo. Por solicitação dessa Dependência, iniciamos as pesquisas naquele local coletando grande número de exemplares dês. ses moluscos, em 9 dos 13 tanques lá existentes, verificando que todos pertensiam à espécie Biomphalaria straminea, em face do exame da concha e dos órgãos genitais masculinos e femininos (Figs. 2, 3 e 4). A concha apresenta um diâmetro aproximado de $1 \mathrm{~cm}$ e o giro corporal volumoso diferindo neste aspecto de $B$. peregrina e $B$. intermedia. Nota-se ainda en- rugamento muito acentuado na parede vaginal que é característico da espécie.

Revestindo-se êste achado de grande significação, em virtude de ser assim acha. da esta espécie pela primeira vez no Estado de São Paulo, resolvemos insistir nas pesquisas indagando da possibilidade de ter sido transportada juntamente com a água na qual são trazidos exemplares de peixes, ou mesmo, pelos próprio peixes. Estendemos as investigações aos outros Postos de Piscicultura que também vêm receliendo peixes procedentes de outros Eslados, aliás, prática muito comum, no intuito de adaptar aos nossos rios as espécies de grande proliferação em outras zo. nas do pais. 0 transporte de peixes é feito por via aérea, em sacos plásticos (Fig. 5), contendo cêrca de 8 litros de água proveniente dos tanques das localidades de origem.

Segundo CorrêA et al. ${ }^{3}$ em junho de 1962 a fauna planorbídica do Estado de 
CORREA, R. de R. et al. - Dispersão de Biomphalaria straminea, hospedeira intermediária do Schistosoma mansoni, através da distribuiçăo de peixes. Rev. Saúde púb1., S. Paulo, 4: 117-27, dez. 1970.

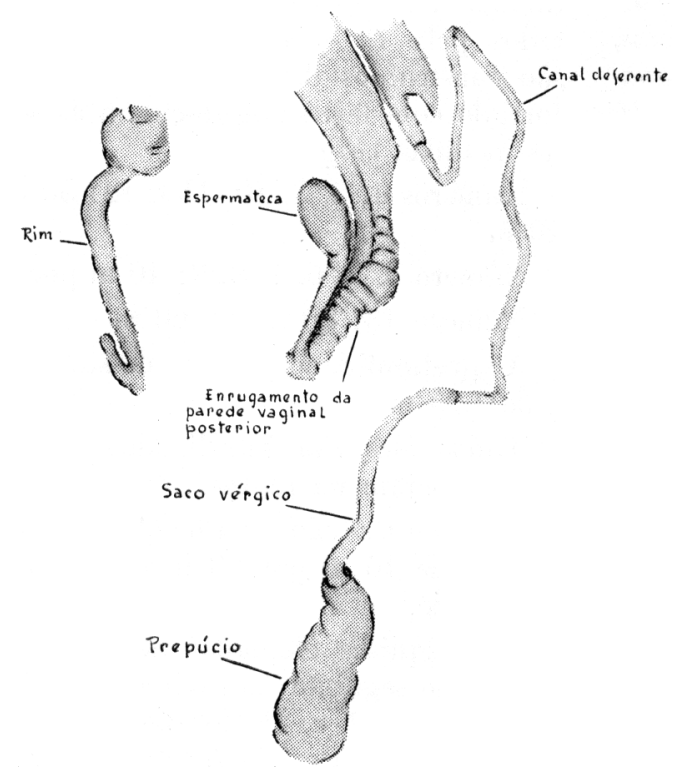

Fig. 2 - orgãos genitais, masculinos e femininos e rim de $R$. straminea.

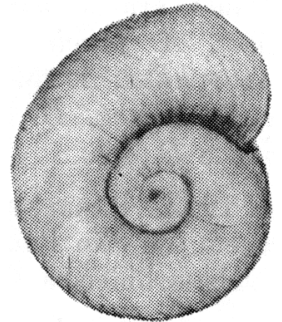

Fig. 3 - Concha de B. straminea - face direita.

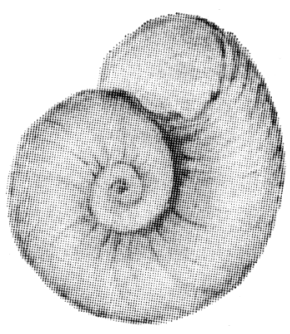

Fig. 4 - Concha de B. straminea - face esquerda.

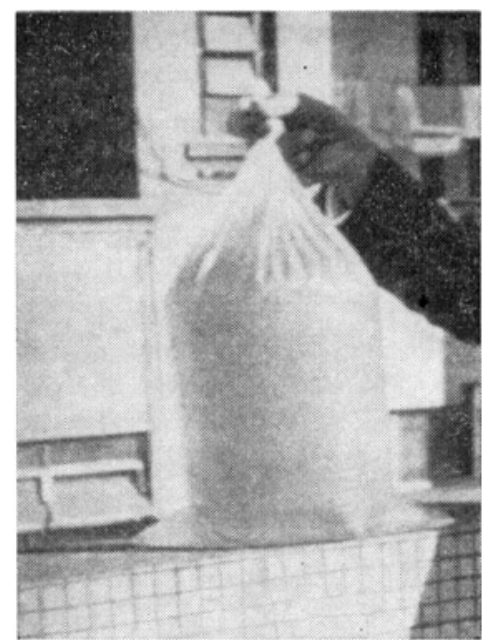

Fig. 5 - Saco plástíco para transporte de peixes. 
CORREA, R. de R. et al. - Dispersão de Biomphalaria straminea, hospedeira intermediária do Schistosoma mansoni, através da distribulção de peixes. Rev. Saúde públ., S. Paulo, 4: 117-27, dez. 1970.

São Paulo era a seguinte: Australorbis glabratus, A. janeirensis, A. peregrinus, A. tenagophilus, $A$. sp. Drepanotrema anatinum, D. cimex, $D$. depressissimum, $D$. melleum e $D$. sp.

Em 1962, Paraense \& Deslandes ${ }^{5}$ descrevem, de Sáo Paulo, uma nova espécie de planorbídeo, a $B$. intermedia.

Com o encontro da $B$. straminea a fauna planorbídica do Estado de São Paulo fica constando de 2 gêneros e 10 espécies e passa a ser a seguinte:

Biomphalaria glabrata (Say, 1818)

Biomphalaria intermedia (Paraense et Deslandes, 1962)

Biomphalaria peregrina (Orbigny, 1835)

Biomphalaria schrammi (Crosse, 1864)

Biomphalaria straminea (Dunker, 1848)

Biomphalaria tenagophila (Orbigny, 1835)

Drepanotrema anatinum (Orbigny, 1837)

Drepanotrema cimex (Moricand, 1837)

Drepanotrema depressissimum (Moricand, 1837)

Drepanotrema lucidum (Pfeiffer, 1839)

Dessas 10 espésies citadas, 3 são hospedeiras intermediárias do Schistosoma mansoni: B. glabrata, B. tenagophila e B. straminea, embora esta última não tenha sido encontrada albergando o parasita em condições naturais no Estado de São Paulo.

Com referência às investigações levadas a efeito, apresentamos os resultados obtidos nas localidades abaixo mencionadas, do Estado de São Paulo.

\section{Barra Bonita}

Estação Experimental de Biologia e Piscicultura, subordinada à Divisão de Pesca Interior do Instituto de Pesca da Secretaria da Agricultura. Situada à margem direita e à montante da Reprêsa de Barra Bonita (Centrais Elétricas de Sáo Paulo) formada pelo represamento das águas do Rio Tietê. Nove dos seus 13 tanques des- tinados à criação de peixes estavam infestados pela $B$. straminea. Esses tanques, são construídos de cimento, com o fundo forrado com terra e apresentam as seguintes medidas (Fig. 6) :

Números 1, 2, 3, 10, 11 e 12: 50 m por $20 \mathrm{~m}$

Número $4,5,6,7,8,9: 10 \mathrm{~m}$ por $20 \mathrm{~m}$

Número $13: 80 \mathrm{~m}$ por $60 \mathrm{~m}$

A profundidade média dêsses tanques: é de $1,25 \mathrm{~m}$

Todos êles são interligados por tuhos que despejam na reprêsa.

Os tanques são abastecidos por caixa d'água de $10 \mathrm{~m}$ por $20 \mathrm{~m}$ e $2 \mathrm{~m}$ de profundidade.

As pesquisas efetuadas nos tanques revelaram o seguinte: nos números $4,5,7,8$, $9,10,11,12$ e 13 foram colhidos 645 exemplares da espécie $B$. straminea, muito embora o número fôsse muito grande, principalmente aderidos às paredes (Fig. 7).

A água excedente dos tanques é conduzida por tubulações até a margem da reprêsa. $\mathrm{Na}$ ocasião de nossas pesquisas o nível da mesma estava muito baixo, fazendo com que a referida água fôsse lan. çada em um leito de terra, que possuia uma extensão aproximada de $10 \mathrm{~m}$. Nêste percurso encontramos grande número de exemplares de $B$. straminea, assim como em um pequeno remanso da reprêsa onde vinha ter a água excedente dos tanques de criação de peixes.

Com a finalidade de estabelecermos a possível área de distribuição nas proximidades da Estação de Piscicultura, conduzimos nossas pesquisas nesta região $\mathrm{da}$ Bacia do rio Tietê, da seguinte maneira:

a) Foi percorrido um trecho de $3.000 \mathrm{~m}$, a jusante da barragem de Barra Bonita não se constatando a presença da $B$. straminea, estendendo-se as pesquisas às margens $\mathrm{e}$ a tôdas as coleções líquidas que cercam o rio Tietê em uma faixa de $\mathbf{2 0 0} \mathrm{m}$ de cada lado.

b) A montande da barragem, percorrendo as margens da reprêsa e suas co- 
CORREA, R. de R. et al. - Dispersão de Biomphalaria straminea, hospedeira intermediária do Schistosoma mansoni, através da distribuição de peixes. Rev. Saúde públ., S. Paulo, 4: 117-27, dez. 1970.

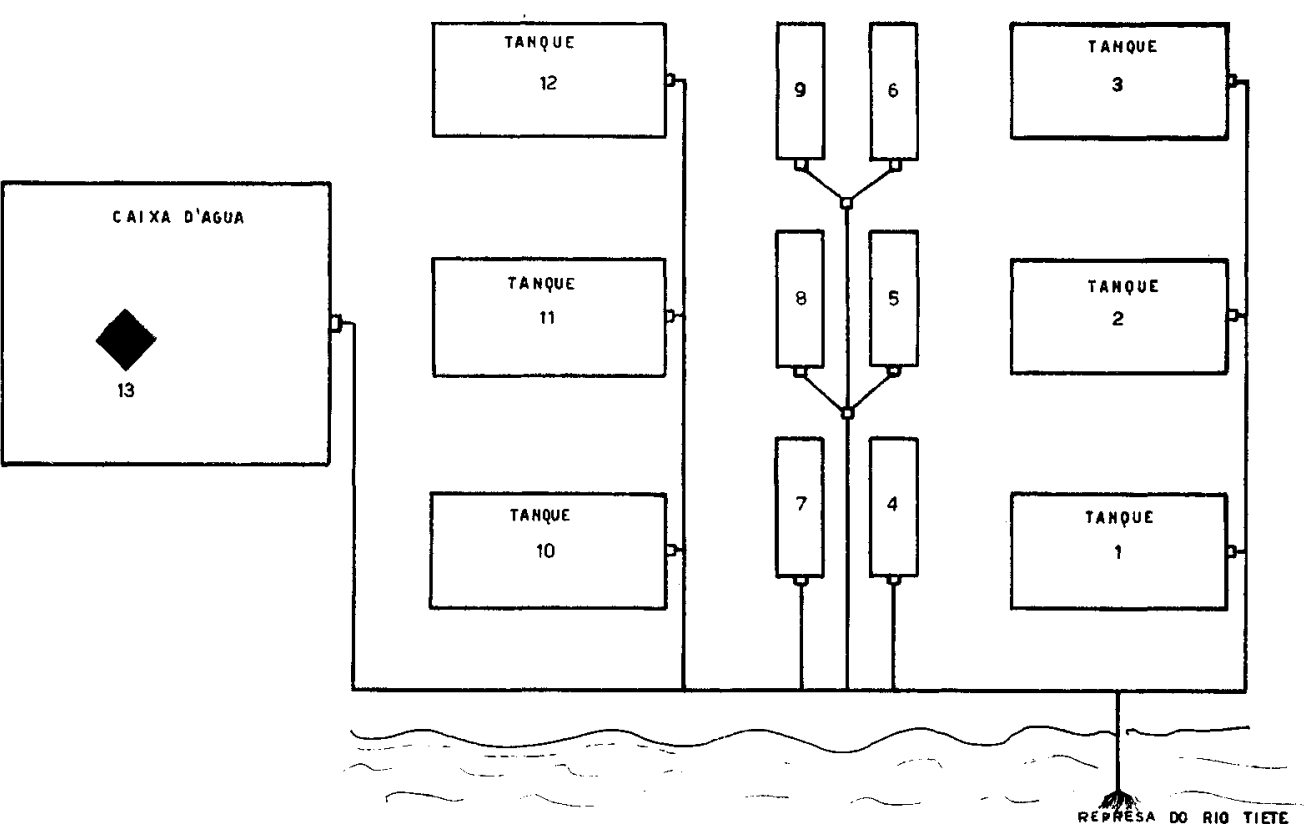

Fig. 6 - Planta esquemática da Estação Experimental de Biologia e Piscicultura de Barra Bonita, Estado de São Paulo. Campanha de Combate à Esquístossomose - Foco de Biomphalaria straminea.

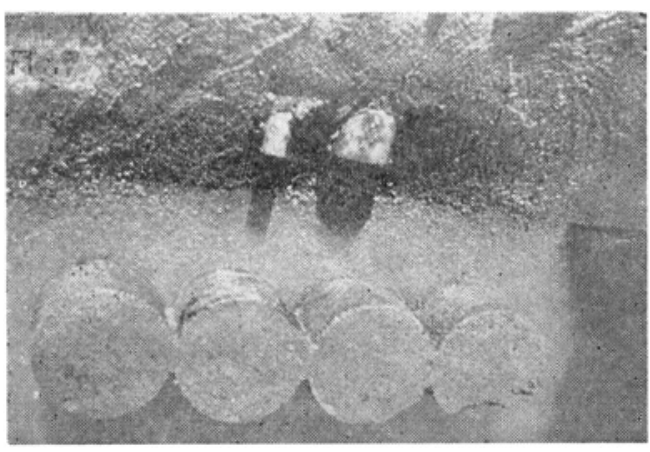

Fig. 7 - Exemplares de $B$. straminea aderidos às paredes de um tanque. 
CORREA, $R$. de $R$. et al. - Dispersão de Biomphalaria straminea, hospedeira intermediária do Schistosoma mansont, atravès da distribuição de peixes. Rev. Saúde públ., S. Paulo, 4: 117-27, dez, 1970.

leções vizinhas, até o $\mathrm{km} 10$, nada se observou em relação a $B$. straminea, a não ser no ponto já citado anteriormente.

Nos locais acima citados foram encontrados sòmente exemplares de $B$. tenagophila e de Drepanotrema cimex.

Através destas buscas, podemos concluir que a $B$. straminea está circunscrita aos tanques da piscicultura, no leito de descarga de água excedente da estação e no remanso na desembocadura desta água.

Os peixes foram importados diretamente de Amanari e Lima Campos no município de Maranguape, Estado do Ceará em dezembro de 1967 e janeiro de 1968. Pertenciam às seguintes espécies: pescada do Piauí (Plasgioscium squamosissum) piabinha (gênero Hemigrammus). $\mathrm{Na}$ mesma ocasião foram importados da mesma procedência, camarões de água doce (Macrobrachium jenskii).

De acôrdo com declaração de um de nós (J. M. Toledo), antes da introdução des. tas espécies importadas, não havia planorhídeos nos tanques de criação notando que, aproximadamente, após 2 meses da introdução das referidas espécies, apareceram um grande número de planorbídeos que povoou intensamente os tanques já enumerados. Rerefe ainda que na ocasião do recebimento dos peixes e camarões não observou a presença de caramujos ou suas desovas nos sacos plásticos.

Tentamos em laboratório, reproduzir as condiçôes de importação. Para tanto, co. letamos água de um dos tanques povoados por B. straminea e deixamos em ohservação durante 2 meses não se regisıtrando o aparecimento de qualquer espécie de planorbídeo.

Observamos que o tanque rom lilapia (Tilapia melunopleura) não apresentava planorlídeo vivo. Verificado êste fato procedemos a necrópsia e exame das víceras, constatando em 4 tilápias examinadas, exemplares íntegros de $B$. straminea, que colocados em aquário mostraram estarem mortos.
No tanque de criação de apaiari (Astronotus ocellatus) encontramos apenas um exemplar vivo de $B$. straminea. Deve-se salientar que nesse tanque, havia um número razoável de conchas vazias dessa espécie.

Ao abrirmos o cano de abastecimento de água de um dos tanques intensamente povoados pela nova espécie de planorbídeo, pudemos colher em tela colocada nesta saída d'água, alguns exemplares de B. straminea. Êsse material coletado, constante dos moluscos e da água, foi coloca. do em aquário de vidro onde observou-se que os planorbídeos estavam vivos. Podemos explicar a presença dêsses, nos canos de abastecimento dos tanques de duas ma. neiras:

1." - Os planorbídeos aí se instalaram subindo da coleção líquida que se encontra aos canos de abastecimentos, cujo desnível com o lençol d'água dos tanques, se torna muitas vêzes igualado;

2:" - existência de planorbídeos na caixa de abastecimento. Os mesmos aí não foram observados. Assinala-se que a água desta caixa é provenien. te da reprêsa de Barra Bonita, sendo o hombeamento feito em um ponto situado aproximadamente a $200 \mathrm{~m}$ da jusante do cano de des. carga dos tanques na mesma mar. grem.

Podemos concluir que a $B$. straminea foi possìvelmente introduzida nesta estação de Piscicultura através da importação de peixes do Ceará, regiāo esta possuidora da espécie de planorbídeos em foco. segundo Barbosa \& Figueiredo:

\section{Americana}

O Pôsto Experimental de Biologia e Piscicultura de Americana, subordinado à Divisão de Pesca Interior do Instituto de 
CORRtA, R. de R. et al. - Dispersão de Biomphalaria straminea, hospedeira intermediária do Schistosoma mansoni, através da distribuição de peixes. Rev. Saúde públ., S. Paulo, 4: 117-27, dez. 1970.

Pesca da Secretaria da Agricultura, situa-se à margem direita e a montante da reprêsa da Companhia Paulista de Fôrça e Luz, no rio Atibaia, no município de Americana.
Apresenta 4 tanques de criação de peixes, construídos de cimento, sendo o fundo coberto por terra (Fig. 8). A profundidade média dos tanques é de $2 \mathrm{~m}$.

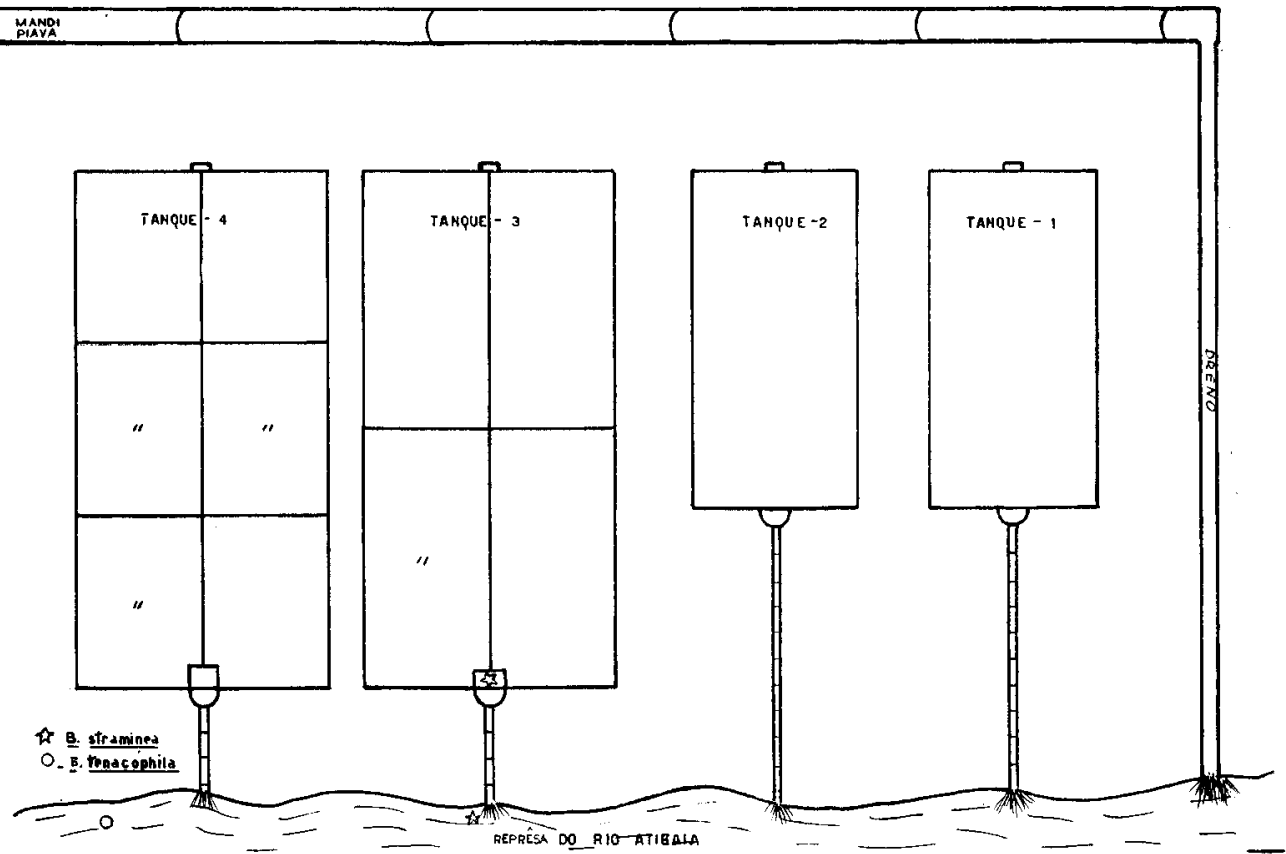

Fig. s - Planta esquemática do Pôsto Experimental de Biologia e Piscicultura de Americana, Estado de São Paulo.

Na ocasião de nossas pesquisas verifica. mos a presença de grande número de exemplares de $B$. straminea na caixa de descarga do tanque 3 , separada do mesmo por tela de nylon com malhas de $3 \mathrm{~mm} \mathrm{x}$ $3 \mathrm{~mm}$. Observamos ainda nas faces das duas comportas voltadas para a referida caixa, uma quantidade enorme de $B$. straminea assim como de suas desovas. No interior do tanque 3 , assim como nos outros inclusive nas respectivas caixas de descargas, não constatamos a presença desta espécie de planorbídeos.

Cada caixa de descarga possui sua saída individual de manilhas até à margem da reprêsa a uma distância de aproximada- mente $5 \mathrm{~m}$. No local de descarga das manilhas do tanque 3 , numa área aproximada de $2 \mathrm{~m}$ de cada lado, nas margens da reprêsa repleta de aguapés, constatou-se ainda a presença de $B$. straminea (15 exemplares) e de $B$. tenagophila (57 exem. plares).

Para avaliarmos a possível disseminação da $B$. straminea nas imediações do Pôsto de Piscicultura, realizamos as seguintes pesquisas:

a) A jusante da barragem da reprêsa, em um trecho de $l \mathrm{~km}$, realizamos pesquisas não encontrando $B$. straminea.

b) A montante da barragem, em trecho de $3 \mathrm{~km}$, em ambas as margens da 
CORREA, R. de $R$. et al. - Dispersão de Biomphalaria straminea, hospedeira intermediaria do Schtstosoma mansoni, através da distribuição de peixes. Rev. Saúde públ., S. Paulo, 4: 117-27, dez. 1970.

reprêsa, não observamos a $B$. stra. minea. Resultou destas pesquisas o encontro de $B$. tenagophila em um trecho de aproximadamente $200 \mathrm{~m}$ acima da desembocadura dos tubos de descarga dos tanques. A $B$. straminea foi encontrada sòmente próxima à desembocadura do cano de descarga do tanque 3 .

Os peixes importados de outra região do país vieram de Amanari e Lima Campos, município de Maranguape do Estado do Ceará em dezembro de 1967, apaiaris (Astronotus ocellatus), transportados nas mesmas condiçōes das espécies de Barra Bonita.

Devido a mudança da chefia neste Pôsto, não pudemos apurar com certeza a época de aparecimento da $B$. straminea.

Pensamos que ela foi também introduduzida nêste Pôsto, da mesma maneira que aquela de Barra Bonita, uma vez que esta espécie acha-se circunscrita ao Pôsto e suas imediações, estando ausente nas coleções líquidas da vizinhança.

\section{São Paulo (município)}

No bairro da Penha, foram encontrados 2 exemplares de $B$. straminea, em um aquário de casa particular cujo morador havia recebido peixes ornamentais procedentes do Estado do Amazonas. Neste Estado, esta espécie já foi assinalada de acôrdo com BARBosa ${ }^{1}$.

\section{Mococa}

$\mathrm{Na}$ Estação Experimental de Biologia e Piscicultura de Limoeiro situa-se a jusante da Barragem da Usina Hidroelétrica de Limoeiro, das Centrais Elétricas de São Paulo, à margem direita do Rio Pardo, no Município de Mococa.

As pesquisas realizadas nesta Estação de Piscicultura revelaram ausência de $B$. straminea, constatando-se a presença das seguintes espécies de planorbídeos: $B$. te- nagophila e $B$. intermedia havendo um predomíneo acentuado da primeira espécie em relação a outra.

Fomos informados que a Estação de Piscicultura recebeu espécie de peixes de Amanari e de Lima Campos, pertencentes a mesma partida enviada à Americana e à Barra Bonita. Por êsse motivo esta Estação ficará sob vigilância.

\section{Pindamonhangaba}

A Estação Experimental de Biologia e Piscicultura de Pinramonhangaba situa-se na Estação Experimental da Produção Animal (Haras Paulista) no município de Pindamonhangaba.

Nesta Estação de Piscicultura não en. contramos a $B$. straminea apesar de ter recebido de Amanari e de Lima Campos no Estado do Ceará, no dia 3 de Janeiro de 1968, as seguintes espécies de peixes: pescada do Piauí (Plasgioscium squamo. sissum), apiari (Astronotus ocellatus) e ainda camarão de água doce (Macrobra. chium jenskii).

Constatou-se nos canais de abastecimento e descarga dos tanques, bem como nas coleções líquidas vizinhas, a presença de $B$. tenagophila em grande número; a vigilância também foi estabelecida, como também nas outras localidades que receberam peixes de regiōes com $B$. straminea.

\section{Jaguariúna}

A Fazenda Santa Rita, situada no Município de Jaguariúna, possui uma estação de piscicultura particular. Recebeu na mesma ocasião de Barra Bonita e Americana, pescada do Piaui (Plasgioscium squamo. sissum) importada da localidade já citada do Nordeste Brasileiro.

Por ocasião de nossa visita não constatamos a presença de planorbíneos nos seus 3 tanques de criação de peixe, bem como nas coleções líquidas vizinhas. 
CORREA, R. de R. et al. - Dispersão de Biomphalaria straminea, hospedeira intermediária do Schistosoma mansoni, através da distribuição de pelxes. Rev. Saúde puibl., S. Paulo, 4: 117-27, dez. 1970 .

\section{São Manoel}

A Secção de Piscicultura da Escola Prática de Agricultura de São Manoel situada no Município do mesmo nome foi pesquisada, uma vez que recebeu da Estação de Piscicultura de Barra Bonita, exemplares de camarão de água doce (Macrobrachium jenshii).

As espécies de planorbídeos encontrados nesta secção foram: $B$. tenagophila, em maior número, seguida por $B$. intermedia em número reduzido, estando ausente a B. straminea.

\section{Pirassununga}

A Estação Experimental de Biologia e Piscicultura de Pirassununga do Ministério da Agricultura, situa-se no Município de Pirassununga nas imediações da. Ca. choeira das Emas.

A única espécie de caramujo encontrada na ocasião de nossa visita, nos vários tanques de criação de peixe, foi a $B$. tenagophila em número reduzido em um tanque não cimentado.

Refere o gerente da Estação que a última importação de peixes realizada diretamente, foi da região Amazônica em 1940, não recebendo mais dêste ano em diante, peixes da referida região ou do nordeste brasileiro.

\section{Salto Grande}

O Pôsto Experimental de Biologia e Piscicultura de Salto Grande situa-se a jusante da reprêsa da Usina Hidroelétrica de Salto Grande, das Centrais Elétricas de São Paulo, no município do mesmo nome.

Nos tanques de criação dêste Pôsto não foi encontrada nenhuma espécie de planorbídeo.

Fomos informados de que o Pôsto não foi suprido por peixes provenientes de outros Estados da Federação.

\section{PROFILAXIA}

Uma vez de posse dos dados expostos passamos a adotar imediatamente as me- didas necessárias ao combate à $B$. straminea, tais como:

\section{a) Barra Bonita:}

E interessante assinalar que o intervalo de tempo decorrido entre a descoberta da nova espécie e seu combate, foi de apenas 20 dias demonstrando a preocupação dos autores em impedir a sua distribuição.

Foi aplicado pentaclorofenato de sódio na dose de 5 p.p.m., em tôdas as cole. ções líquidas povoadas por $B$. straminea, inclusive na caixa de abastecimento, embora não estivesse infestada. Houve mortalidade total dos peixes que povoavam os tanques tratados.

\section{b) Americana:}

Aplicou-se Bayluscíd (5-2' dicloro-4' nitro salicilanilida) na dose de 0,3 p.p.m. em tôdas as coleções líquidas com $B$. straminea, constatando-se mortalidade desta espécie.

Ambas as Estações de Piscicultura estão sob o contrôle da Campanha de Combate à Esquistossomose e após 3 meses de aplicação de moluscocidas não se observou o aparecimento dessa espécie recém introduzida no Estado de São Paulo.

\section{c) Säo Paulo (município)}

O aquário particular, onde havia apenas 2 exemplares, foi mantido sob vigilância recomendando ao seu proprietário não enviar peixes ou plantas para outros locais.

\section{COMENTARIOS E CONCLUSOES}

Até o presente, os trabalhos de coleta de planorbídeos para a confecção da carta de distribuição geográfica do Estado realizados em 226 municípios, revelaram a ocorrência das duas espécies hospedeiras inter- 
CORREA, R. de R. et al. - Dispersão de Biomphalaria straminea. hospedeira intermediária do Schistosoma mansoni, através da distribuição de peixes. Rev. Saúde públ., S. Paulo, 4: 117-27, dez. 1970.

mediárias do Schistosoma mansoni: $B$. te. nagophila e $B$. glabrata.

Nas pesquisas atuais foi encontrada a B. straminea em condiçóes ecológicas que permitem afirmar ter sido esta espécie introduzida em nosso Estado através de transporte de peixes importados de áreas onde ela ocorre, isto é, os Estados do Amazonas e Ceará, muito embora os técnicos das Estaçóes de Piscicultura não tenham observado caramujos na água dos recipien. tes utilizados para o transporte dos peixes.

A importação dêsses peixes tem a finalidade de pesquisar a sua adaptação às coleçóes hídricas. A ocorrência foi verificada nas Estações de Piscicultura de Barra Bonita e Americana, e em um aquário de casa particular em São Paulo. Isto vem corroborar a observação sôbre o perigo que representa a distribuição de peixes e a maneira como ela vem sendo realizada.

A gravidade do problema decorre não só da importação da espécie mencionada como também de sua disseminação para todo o Estado, graças à redistribuição às Estações de Piscicultura e a particulares. Deve ser acrescentado que esta disseminação pode também ser feita através dos rios em cujas margens se localizam os tanques de criação de peixes, conforme foi referido linhas atrás.

Esta ocorrência foi levada ao conhecimento do Departamento Nacional de Endemias Rurais para as necessárias providências, junto aos órgãos competentes. Uma das medidas que poderá ser preconizada é a obrigatoriedade da quarentena para os peixes oriundos de zonas infestadas por espécies de planorbídeos hospedeiros intermediários do $S$. mansoni.

A dispersão passiva da $B$. straminea pelo transporte de peixes, deve ampliar a distribuição geográfica dêsse planorbídeo que já foi assinalado na Venezuela, Guianas e no Brasil ${ }^{4}$ sendo que, neste último, ocorre em tôdas as Unidades Federativas, exceto no Rio Grande do Sul, Santa Catarina, Rio de Janeiro e Territórios.
Foram examinados 217 exemplares de $B$. straminea todos negativos para cercárias do Schistosoma mansoni.

Corrêa, R. de R. et al. - [The spreading of Biomphalaria straminea, intermediate host of Schistosoma mansoni through the distribution of fishes]. Rev. Saude pribl., S. Paulo, 4:117-28, dez. 1970.

SUMmary - Up the present, the works of collecting planorbids done in 226 municipalities for the elaboration of the geographical distribution chart in the State of São Paulo (Brazil), showed the presence of two intermediate host species of Schistosoma mansoni: Biomphalaria tenagophila and Biompralaria glabrata. Although the technicians from the Psiculture Stations, have not found snails in the water inside the containers used for the transportation of fishes, the ecological conditions of $B$. straminea in the latest researches are such as to indicate that they have been introduced, in our State through fish transportation imported from areas where it occurs, such as the State of Amazonas and Ceará (Brazil). The aim of the importation of these fishes is its adaptation to local waters. The occurrence was noticed in the Psiculture Stations of the towns of Barra Bonita and Americana, and in an aquarium of a private house in the city of São Paulo. This shows the danger that the distribution of fishes represents and the way it is being done. The seriousness of the problem originates not only from the importation of the said species but also from its dissemination in the State, through the redistribution to the private Psiculture Stations. It should be remembered that this dissemination can be also done through rivers in which banks are located tanks for the breeding of fishes as mentioned before. This facts was communicated to the National Department of Rural Endemies for the necessary measures. One of the steps to be taken should be the quarentine for fishes from zones infested with species of planorbids hosts of $S$. mansoni. The passive scattering of $B$. straminea by the transportation of fishes, will enlarge the geographical distribution of these planorbids, which have already been found in Venezuela, Guianas and Brazil. In this last country it is found in all its States with the exception of Rio Grande do Sul, Santa Catarina, Rio de Janeiro and Federal Territories. 
CORREA, R. de R. et al. - Dispersão de Biomphalaria straminea, hospedeira intermediária do Schistosoma mansoni, através da distribuição de peixes. Rev. Saúde públ., S. Paulo, 4: 117-27, dez. 1970.

Two hundred and seventeen specimens of $B$. straminea were examined and all of them were negative to cercaries of shistosoma mansoni.

\section{A GRADECIMENTOS}

Ao Dr. Cirilo E. de Mafra Machado, das Centrais Elétricas de São Paulo, pela colaboração durante nossos trabalhos nas Estações de Piscicultura.

Ao Dr. José Maria Bramley Barker, biologista chefe da Secção de Biologia Aquática e Aqüicultura do Instituto de Pesca da Secretaria da Agricultura, pelas informações e facilidades oferecidas nas Estações de Piscicultura.

Ao Professor Dr. W. Lobato Paraense, na confirmação sistemática da $B$. straminea em São Paulo.

\section{REFERENCIAS BIBLIOGRÃFICAS}

1. BARBOSA, F. S. - A note on Biomphalaria straminea (Dunker, 1848) from Manaus,
State of Amazonas, Brazil. Rev. Soc. bras. Med. trop., 2:77-8, mar. 1968.

2. BARBosA, F. S. \& FIGUEIREDO, T. Geographical distribution of snail hosts of schistosomiasis mansoni in northeastern Brazil. Rev. Inst. Med. trop. S. Paulo, 11:285-89, jul. 1969.

3. CORREA, R. de R. et al. - Planorbideos do Estado de São Paulo. Sua relação com a esquistossomose (Pulmonata, Planorbidae). Arq. Hig., S. Paulo, 27:139-59, jun. 1962.

4. PAN AMERICAN HEALTH ORGANIZATION - A guide for the identification of the snail intermediate hosts of Schistosomiasis in the Americas. Washington, D.C., 1968. (Scientific Publication, 168).

5. PARAENSE, W. L. \& DESLANDES, N. Australorbis intermedius 2 s.p.n. from Brazil (Pulmonata, Planorbidae). Rev. bras. Biol., 22:343-50, dez. 1962.

6. REY, L. - Contribuição para o conhecimento aa morfologia, biologia e ecologia dos planorbideos brasileiros transmissores da esquistossomose. Sua importancia em epidemiologia. Rio de Janeiro, Serviço Nacional de Educacão Sanitária, 1956. 